\title{
Invitro Effect of Bulkfill and Incremental Application Techniques with Different Composite Filling Materials on Marginal Microleakage
}

\author{
Aulfat A. Albahari ${ }^{*}\left(\mathbb{D}\right.$, Ahmed A. Madfa $^{2,3}$, Mohammed A. Dubais ${ }^{1}$ \\ ${ }^{1}$ Restorative Dentistry and Prosthodontics Department, Facultyof Dentistry, University of Science and \\ Technology, Sana'a, Yemen \\ 2Department of Conservative Dentistry, College of Dentistry, Thamar University, Dhamar, Yemen \\ ${ }^{3}$ Department of Restorative Dentistry, College of Dentistry, University of Hail, Hail, Kingdom of Saudi Arabia
}

\begin{abstract}
Objective: To assess the in vitro effect of bulkfill and incremental application techniques on the microleakage of class II dental cavities filled with three different bulkfill composite materials at occlusal and cervical margins.

Methods: Standardized class II cavities were prepared on 120 human premolar teeth extracted for orthodontic treatment, which were randomly divided into two main groups of 60 teeth, corresponding to the two application techniques. Each group wasthen sub-dividedrandomly into three sub-groups based on the type of bulkfill restorative materials as follows: Tetric ${ }^{\circledR} \mathrm{N}$ Ceram BulkFill, Filtek ${ }^{\mathrm{TM}}$ BulkFill flowable restorative material and X-trafil ${ }^{\circledR B}$ BulkFill. All cavities were prepared and etched, and the corresponding self-etch bond adhesive systems were applied. A stereomicroscope was used to assess microleakage after thermocycling and immersion of the specimens in $0.1 \%$ methylene blue for 24 hours. Mann-Whitney U test was then used to analyze data.

Results: No statistically significant difference was found in the marginal microleakage between the incremental and bulkfill techniques using the three types of composite materials at both occlusal and cervical margins. The X-trafil ${ }^{\circledR}$ BulkFill showed the lowest score of microleakage with both application techniques compared to other bulkfill composite materials.

Conclusion: Both incremental and bulkfill application techniques using Tetric ${ }^{\circledR} \mathrm{N}-\mathrm{Ceram}_{\text {BulkFill, Filtek }}{ }^{\mathrm{TM}}$ BulkFill flowable restorative material and X-trafil ${ }^{\circledR}$ BulkFill composite materials have a comparable effect on the marginal microleakage at occlusal and cervical margins of human teeth extracted from dental clinics in Sana'a city. Further studies are recommended to assess the clinical success of bulkfill composite materials using SEM or confocal microscope.
\end{abstract}

Keywords: Microleakage; Dental application technique; Bulkfill composite material; Cervical margin; Occlusal margin

\section{*Corresponding Author:A. A.Albahari (aulfatalbahari2013@yahoo.com)}




\section{Introduction}

The stability and success of resin composite restorations depend on their marginal seal and the absence of microleakage. However, polymerization shrinkage still represents a major disadvantage. ${ }^{(1,2)}$ This shrinkage affects marginal sealing and allows the ingress of oral fluids, microorganisms, and other molecules to the cavity walls and restoration interface.(3) Furthermore, the volumetric changes differ between the restoration and the tooth structure because of the differences in the thermal expansion coefficient during temperature changes, directly affecting microleakage.(4)

Studies have focused on improving placement techniques, materials and composite formulation, primarily the polymetric matrix, to reduce polymerization shrinkage and polymerization shrinkage stress.(5) Although low-shrinking composite resins are desirable, several factors determine the shrinkage stress of a restoration such as cavity geometry, material type and application technique.(6)

Several techniques have been developed to avoid the effect of polymerization shrinkage and microleakage, including incremental layering application, light curing of the composite restoration of less than $2 \mathrm{~mm}$ thickness, ${ }^{(1,2)}$ and the use of indirect and semi-direct restorations.(7) However, nonear highly successful in reducing the occurence of polymerization shrinkage.

The incremental filling remains the "gold standard" technique to restore dental cavities exceeding $2 \mathrm{~mm}$ in depth. This technique minimizes gap formation and polymerization stress, allows adequate bonding of composite to tooth tissue and ensures complete polymerization of resin-based composites.(8) Furthermore, the incremental application of composite filling material can reduce $\mathrm{C}$-factor and, hence,the shrinkage stress at the tooth restoration margin by allowing the stress-relieving flow of composite restoration from the unbonded surface to the bonded one.(9)
Posterior composite application techniques are time-consuming, and the adaptation may be difficult when they extend below the cemento-enamel junction (CEJ). An increased marginal leakage could when the cervical finishing line is positioned below the CEJ.(10,11) To overcome this leakage, the use of flowable composites is recommended because of the increased elasticity, wettability, and low viscosity that improve the marginal adaptation of composite restorations. (6) However, flowable composites are not suitable filling materials for all types of restorations due to their lower physical and wear resistance properties. Furthermore, most conventional composite filling materials exhibit lower polymerization shrinkage when compared to flowable composites.

It has been claimed that the recently introduced bulkfill composites could be a solution for polymerization shrinkage and microleakage. These materials are suitable for application in a $4 \mathrm{~mm}$ thickness composite due to their high reactivity to light curing, low polymerization stress and improved mechanical and chemical characteristics. ${ }^{(12)}$

Class II cavity restorations with composite filling materials have been controversial, particularly in preparations under the cervical margin where there is no enamel and the cavity margins are formed of dentin, cementum or both. The use of the multiple layering application technique is recommended to resist resin composite shrinkage stress and improve marginal adaptation. ${ }^{(13,14)}$ On the contrary, some studies proved that the mono-incremental application (bulk) of composite filling materials minimizes the marginal leakage due to less contraction stress induction.(15,16) Therefore, the present study compared the effect of incremental and bulkfill application techniques on the marginal microleakage of class II cavities restored with three different composite restorative materials. 


\section{Methods}

\subsection{Specimen preparation}

One hundred and twenty human premolar teeth extracted within three months were examined under a magnifying lens to detect any enamel cracks or fissures. The teeth were cleaned from the blood and soft tissue, and then immersed in $0.1 \%$ chloramine $\mathrm{T}$ solution for one week and then in normal saline solution. Self-curing acrylic resin was used to make manipulation blocks at the roots of each tooth to facilitate its handling. Light-cured composite was then used to fix the tooth on metallic holders.Thereafter, normal saline was the medium for storing teeth at room temperature.

\subsection{Cavity preparation}

Standardized class II cavities with parallel walls were prepared on all teeth. An individual metal matrix band was adapted and a periodontal probe was used with the cervical finishing line established at $1 \mathrm{~mm}$ underneath the CEJ. The preparation dimension was settled at $4 \mathrm{~mm}$ bucco-lingually and $4 \mathrm{~mm}$ occluso-gingivally with a cavity depth of $2 \mathrm{~mm}$. Cavities were prepared using rough diamond burs (F80710M, ökoDENT, Thuringia, Germany) in an air/water-cooled high-speed turbine (W\&H, Bürmoos, Austria) with finishing diamond burs (\#2203, Dentex, Taipei, Taiwan). The enamel cavity margins and inner angles of the cavities were then rounded and beveled. The preparations were then checked for standardization using a periodontal probe, and an air/water stream was used for cleaning.

\subsection{Specimen restoration}

The specimens were divided randomly into two main groups; namely, incremental and bulkfill application techniques (60 specimens per group). Each group was sub-divided randomly into three equal sub-groups based on the various restorative bulkfill materials (Figure 1).

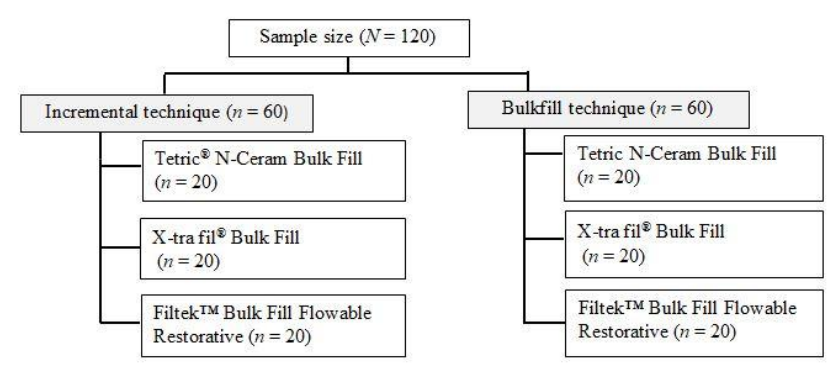

Figure1. Flowchart of group and sub-group allocation of specimen restorations

The specificationsof the materials used in the preparation of specimen restorations are shown in Table (1).

Table 1. Specifications of the materials used in preparing specimen restorations

\begin{tabular}{|c|c|c|c|}
\hline Material & $\begin{array}{l}\text { Manufac- } \\
\text { turer }\end{array}$ & Composition & $\begin{array}{l}\text { City } \backslash \text { Coun- } \\
\text { try }\end{array}$ \\
\hline $\begin{array}{l}\text { Tetric }{ }^{\circledR} \text { N-Ce- } \\
\text { ram Bulk Fill }\end{array}$ & $\begin{array}{l}\text { Ivoclar } \\
\text { Vivadent }\end{array}$ & $\begin{array}{l}\text { BIS-GMA, urethane } \\
\text { dimethacrylate, bar- } \\
\text { ium glass filler, ivo- } \\
\text { cerin, shrinkage } \\
\text { stress reliever, light } \\
\text { sensitivity filter- } \\
\text { filler, pigments }\end{array}$ & $\begin{array}{l}\text { Liechten- } \\
\text { stein, Ger- } \\
\text { many }\end{array}$ \\
\hline $\begin{array}{l}\text { Filtek }^{\mathrm{TM}} \\
\text { Bulk Fill } \\
\text { Flowable } \\
\text { Restorative }\end{array}$ & 3M ESPE & $\begin{array}{l}\text { BIS-GMA, urethane } \\
\text { dimethacrylate, } \\
\text { procrylat resin fill- } \\
\text { ers; a combination } \\
\text { of zirconia /silica } \\
(0.01 \text { to } 3.5 \mu \mathrm{m}) \text { and } \\
\text { ytterbium trifluo- } \\
\text { ride }(0.1 \text { to } 5 \mu \mathrm{m})\end{array}$ & $\begin{array}{l}\text { St. Paul, } \\
\text { MN, USA }\end{array}$ \\
\hline $\begin{array}{l}\text { X-trafil }{ }^{\circledR} \\
\text { Bulk Fill }\end{array}$ & Voco & $\begin{array}{l}\text { BIS-GMA, urethane } \\
\text { dimethacrylate, } \\
\text { TEGDMA }\end{array}$ & $\begin{array}{l}\text { Cuxhaven, } \\
\text { Germany }\end{array}$ \\
\hline
\end{tabular}

A 37.0\% phosphoric acid gel solution (Ivoclar Vivadent, Liechtenstein, Germany) was applied for 30 seconds on enamel and 15 seconds on dentin for etching the cavity surfaces. The cavity surfaces were then washed with a water jet for 5 seconds and dried with a gentle stream of air, leaving a moistened surface. A microbrush was used to apply the corresponding self-etch bond adhesive systems;namely, Adhe SE One F (Ivoclar Vivadent, Liechtenstein, Germany), Scotch Bond Universal (3M ESPE, St. Paul, MN, USA) and Futurabond DC (Voco, Cuxhaven, Germany).Ten seconds were set as the curing time. 
A light-emitting diode (LED) light-curing unit (LY-C240, Foshan City, China) with a $1200 \mathrm{mw} \backslash \mathrm{cm}^{2}$ light intensity was applied on each specimen. The distance between the LED light-curing unit and the specimens was standardized having the light guide tip $10 \mathrm{~mm}$ away from the margins of cavities. The LED light-curing unit was constantly monitored before the application of the restorations by a radiometer (Dymax, Torrington, USA).

The proximal wall was built up during composite placement using a metallic matrix. For the bulkfill technique, specimens were restored with a composite of $4 \mathrm{~mm}$ thickness in a single step. For the incremental technique, specimens were restored with a composite of $2 \mathrm{~mm}$ thickness. The curing time for each specimen in both techniques was 40 seconds. Afterwards, flexible disks (3M ESPE, St. Paul, MN, USA) were used for finishing and polishing. The specimens were kept in normal saline throughout the experiment to avoid dehydration.

All cavities were prepared and restored by the same experienced operator. The teeth were thermocycled for 1000 thermal cycles between two water baths at $55^{\circ} \mathrm{C}$ and $5^{\circ} \mathrm{C}$ with a dwell time of 30 seconds. ${ }^{(17)}$

\subsection{Microleakage testing}

Once thermocycling was completed, two layers of nail polish were used to cover all the specimens, except $1 \mathrm{~mm}$ above and below the border between the restoration and the tooth structure. Afterwards, the specimens were immersed in $0.1 \%$ methylene blue for 24 hours. Then, the specimens were rinsed, dried at room temperature and mesiodistally cut through the central line of the restoration with a slow speed dental micro-motor (300 rpm) using a diamond disk under constant cooling.

The specimens were observed under a binocular optical zoom stereomicroscope (Motic, Wetzler, Germany) adapted with a digital camera at $45 \mathrm{x}$ magnification. The dye penetration degree along the cervical and occlusal margins was then recorded and scored according to the penetration percentage usingthe following formula:

$$
\text { Microleakage } \%=\frac{\text { Dye penetration from the outer margin }}{\text { Total surface of the restoration }}
$$

The microleakage scores used in this study were based on the method proposed by Radhika et al.(13) as shown in Table (2).

Table 2. Microleakage scoring used in this study

\begin{tabular}{ll}
\hline Microleakage & Indication \\
scores & \\
\hline $\begin{array}{c}\text { Scoring for occlusal } \\
\mathbf{1}\end{array}$ & $\begin{array}{l}\text { Noll dye penetration } \\
\text { Dye penetration into half extension of the } \\
\text { occlusal wall }\end{array}$ \\
$\mathbf{2}$ & $\begin{array}{l}\text { Dye penetration into more than half of oc- } \\
\text { clusal wall }\end{array}$ \\
$\mathbf{3}$ & Dye penetration into pulpal wall \\
$\mathbf{S c o r i n g}$ for cervical wall & No dye penetration \\
$\mathbf{0}$ & $\begin{array}{l}\text { Dye penetration into half extension of the } \\
\text { cervical wall }\end{array}$ \\
$\mathbf{2}$ & $\begin{array}{l}\text { Dye penetration into more than half or com- } \\
\text { plete extension of the cervical wall }\end{array}$ \\
$\mathbf{3}$ & $\begin{array}{l}\text { Dye penetration into cervical and axial walls } \\
\text { towards the pulp }\end{array}$ \\
\hline
\end{tabular}

An image software tool (ScopePhoto 3.0, Microscope World, CA, USA) was used to assess the percentage of dye penetration relative to the total length of the restoration.

\subsection{Statistical analysis}

Data were analyzed using IBM SPSS Statistics, version 25.0 (IBM Corp., Armonk, NY, USA). The reliability test was performed after two weeks of re-examination of $20 \%$ of the specimens using the Cronbach's alpha coefficient $(\alpha)$ test. Descriptive Statistics and Mann-Whitney $U$ test were performed, as appropriate, to achieve the various objectives. Differences were considered statistically significant at $P$-values $<0.05$.

\section{Results}

Accepted readings of reliability $(86.0 \%)$ were reported. No significant difference was found in microleakage between the incremental and the bulkfill techniquesat occlusal $(P=0.450)$ and cervical $(P=0.759)$ margins (Table 3). 
Table 3.Microleakage score comparison between incremental and bulkfill application techniques at occlusal and cervical margin

\begin{tabular}{lllll}
\hline $\begin{array}{l}\text { Mar- } \\
\text { gins }\end{array}$ & $\begin{array}{l}\text { Tech- } \\
\text { nique }\end{array}$ & Z-score & Mean \pm SD & $P$-value \\
\hline & Incremen- & & $0.71 \pm 0.487$ & \\
Occlu- & tal & -.755 & $1.00 \pm 0.495$ & 0.450 \\
sal & Bulkfill & & & \\
& & $0.91 \pm 0.516$ & \\
\multirow{2}{*}{$\begin{array}{l}\text { Cervi- } \\
\text { cal }\end{array}$} & $\begin{array}{l}\text { Incremen- } \\
\text { tal }\end{array}$ & & $1.00 \pm 0.502$ & \\
\hline
\end{tabular}

Table (4) shows that the occlusal margin microleakage was significantly lower than cervical margin microleakageacross all groups $(P<0.001)$.

Table 4. Microleakage comparison between occlusal and cervical

\begin{tabular}{|c|c|c|c|c|}
\hline \multirow[t]{2}{*}{$\begin{array}{l}\text { Marginal mi- } \\
\text { croleakage }\end{array}$} & $\begin{array}{l}\text { Mann- } \\
\text { Whit- } \\
\text { ney U }\end{array}$ & $\begin{array}{l}\text { Occlusal } \\
\text { margin } \\
\text { Mean }\end{array}$ & $\begin{array}{l}\text { Cervical } \\
\text { margin } \\
\text { Mean }\end{array}$ & $P$-value \\
\hline & 1395.00 & 54.64 & 78.36 & $0.001^{*}$ \\
\hline
\end{tabular}

Table (5) shows the scores of occlusal and cervical marginal microleakage according to the application techniques and the bulkfill composite materials. The X-trafil ${ }^{\circledR B}$ BulkFill showed the lowest microleakage percentage among the experimental groups (9.1\%), with $1 \mu \mathrm{m}$ dye penetration, whereas Fil-

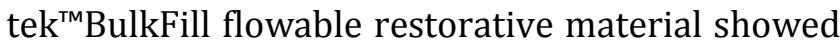
the highest microleakage percentage (90.9\%) with a $10 \mu \mathrm{m}$ dye penetration.

Table 5.Total dye penetration $(\mu \mathrm{m})$ and microleakage (\%) comparison between the three bulkfill composite materials

\begin{tabular}{|c|c|c|c|c|c|c|}
\hline \multirow[t]{2}{*}{ Variables } & \multirow[t]{2}{*}{ Application techniques } & \multirow[t]{2}{*}{ Scores } & \multirow[t]{2}{*}{ Margins } & \multicolumn{3}{|l|}{ Materials } \\
\hline & & & & Filtek $^{\mathrm{TM}}$ Flowable & Tetric ${ }^{\circledR} \mathrm{N}$-Ceram & X-trafill ${ }^{\circledR}$ \\
\hline \multirow{10}{*}{$\begin{array}{l}\text { Dye penetration } \\
(\mu \mathrm{m})\end{array}$} & \multirow{5}{*}{ Incremental } & \multirow[t]{2}{*}{0} & Occlusal & 1 & 4 & 6 \\
\hline & & & Cervical & 1 & 1 & 2 \\
\hline & & \multirow[t]{2}{*}{1} & Occlusal & 10 & 7 & 5 \\
\hline & & & Cervical & 10 & 9 & 9 \\
\hline & & 2 & Cervical & 1 & 2 & 1 \\
\hline & \multirow{5}{*}{ Bulkfill } & \multirow[t]{2}{*}{0} & Occlusal & 3 & 5 & 6 \\
\hline & & & Cervical & 1 & 2 & 1 \\
\hline & & \multirow[t]{2}{*}{1} & Occlusal & 8 & 6 & 5 \\
\hline & & & Cervical & 7 & 9 & 1 \\
\hline & & 2 & Cervical & 4 & 1 & 1 \\
\hline \multirow{10}{*}{ Microleakage \% } & \multirow{5}{*}{ Incremental } & \multirow[t]{2}{*}{0} & Occlusal & $9.1 \%$ & $36.4 \%$ & $54.5 \%$ \\
\hline & & & Cervical & $9.1 \%$ & $9.1 \%$ & $18.2 \%$ \\
\hline & & \multirow[t]{2}{*}{1} & Occlusal & $90.9 \%$ & $63.6 \%$ & $45.5 \%$ \\
\hline & & & Cervical & $90.9 \%$ & $81.8 \%$ & $81.8 \%$ \\
\hline & & 2 & Cervical & $9.1 \%$ & $18.2 \%$ & $9.1 \%$ \\
\hline & \multirow{5}{*}{ Bulkfill } & \multirow[t]{2}{*}{0} & Occlusal & $27.3 \%$ & $45.5 \%$ & $54.5 \%$ \\
\hline & & & Cervical & $9.1 \%$ & $18.8 \%$ & $9.1 \%$ \\
\hline & & \multirow[t]{2}{*}{1} & Occlusal & $72.7 \%$ & $54.5 \%$ & $45.5 \%$ \\
\hline & & & Cervical & $63.6 \%$ & $9.1 \%$ & $9.1 \%$ \\
\hline & & 2 & Cervical & $36.4 \%$ & $9.1 \%$ & $9.1 \%$ \\
\hline
\end{tabular}

Table (6) shows a significant difference between the occlusal and cervical margins with respect to Filtek ${ }^{\mathrm{TM}}$ BulkFill Flowable Restorative $(P=0.031)$ and Tetric ${ }^{\circledR} \mathrm{N}$-Ceram $(P=0.051)$.
Table 6. Microleakage scores of the three composite materials applied in bulkfill and incremental techniques at occlusal and cervical margins

\begin{tabular}{|c|c|c|c|c|c|c|}
\hline \multirow[t]{2}{*}{ Margins } & \multirow{2}{*}{$\begin{array}{l}\text { Bulkfill } \\
\text { materi- } \\
\text { als }\end{array}$} & \multicolumn{2}{|c|}{ Bulkfill application } & \multicolumn{2}{|c|}{$\begin{array}{l}\text { Incremental applica- } \\
\text { tion }\end{array}$} & \multirow[t]{2}{*}{$P$-value } \\
\hline & & Mean \pm SD & $\begin{array}{l}\text { me- } \\
\text { dian }\end{array}$ & Mean \pm SD & median & \\
\hline \multirow[t]{3}{*}{ Occlusal } & Filtek $^{\mathrm{TM}}$ & $0.91 \pm 0.32$ & 1.0 & $0.73 \pm 0.47$ & 1.0 & 0.280 \\
\hline & $\begin{array}{l}\text { Tetric }{ }^{\circledR N} \text { - } \\
\text { Ceram }\end{array}$ & $0.64 \pm 0.51$ & 1.0 & $0.55 \pm 0.52$ & 1.0 & 0.672 \\
\hline & X-trafil ${ }^{\circledR}$ & $0.45 \pm 0.52$ & 0.0 & $0.45 \pm 0.52$ & 0.0 & 1.000 \\
\hline \multirow[t]{3}{*}{ Cervical } & Filtek $^{\mathrm{TM}}$ & $1.0 \pm 0.01$ & 1.0 & $1.36 \pm 0.51$ & 1.0 & 0.031 \\
\hline & $\begin{array}{l}\text { Tetric }{ }^{\circledR N} \text { - } \\
\text { Ceram }\end{array}$ & $1.18 \pm 0.41$ & 1.0 & $0.91 \pm 0.30$ & 1.0 & 0.051 \\
\hline & X-trafil ${ }^{\circledR}$ & $0.82 \pm 0.41$ & 1.0 & $0.82 \pm 0.41$ & 1.0 & 0.544 \\
\hline
\end{tabular}

$\mathrm{SD}$, standard deviation. 


\section{Discussion}

Several techniques have been developed to estimate the microleakage of restorative materials both in vivo and in vitro. In vivo studies remain the first choice in evaluating the performance of dental materials, butthis choice is time-consuming and the standardization of procedures is somehow difficult.(18)Therefore, in vitro microleakage studies are an important tool to evaluate gap formation.(18) The present study used natural human teeth and clinical protocols to simulate the clinical situation of invivo studies to some extent.

Scanning electron microscope (SEM) and stereomicroscope have been used to assess the marginal seal and microleakage of direct and indirect composite inlays in cavities with cervical margin set in enamel or dentin. ${ }^{(19)}$ No significant differences were found between both techniques when the cervical margin was in enamel. However, for the cervical margin in dentin, the direct technique showed more microleakage than the indirect technique.(19)The present study choseclass II restorations with $1 \mathrm{~mm}$ cervical extension below the CEJ as an appropriate design for evaluating the sealing ability. Moreover, the longitudinal mesiodistal sectioning of the class II cavities permits the assessment of both cervical and occlusal leakage simultaneously.

To simulate clinical conditions, extracted intact human teeth were used in this investigation. Thermocycling was also used toexposeteeth and restoration to temperature changes and, in turn, to simulate the aging of the restorations in the mouth. This imitates the temporary cold and hot temperatures in the mouth and spots the thermal expansion differences between the restoration and the tooth, which may cause gap formation. ${ }^{20)}$

Various methods have been used for microleakage assessment, including air pressure, bacterial studies, radioisotope, neutron activation, dye penetration, SEM and electrochemicalmethods.(21, 22) Among these methods, the dye penetration test is known to beeffective for determining marginal gaps in experimental studies. It is the most commonly used method for determining marginal leakage in vitro, after a longitudinal cut of teeth. This method was preferred for this study because of its ease and frequent use in the published literature.(23)

The present study revealed no significant difference in microleakage percentagebetween the incremental andbulkfill application techniques with thethree different composite resins. This finding is in agreement with that byRengo et al.(24), who reportedno significant differences in the marginal leakage of bulkfill composites in class II restorations. Similarly, Idriss et al.(25), who reported thatthe marginal adaptation of class II composite restorations is not affected by using mono-incremental and multiple-incremental application techniques. They also reported that there was no significant difference in marginal microleakage between the bulkfill and incremental application techniques in vitro. On the other hand, the present findings are in disagreement withthatbyKuijs et al.(26), who showed higher polymerization shrinkage with the layering technique. This could be attributed to the differences in the study design and restorative materials used.

In the present study, microleakage scores were higher in the cervical margins than the occlusal margins independent of the composite material. This can be attributed to the histological, compositional and morphological differences of the two sites. Poggio et al.(27)evaluated class II microleakage of conventional and bulkfill composite restorative materials with their gingival margin underneath the CEJ, and all composite restorations showed microleakage similar to this study.

Patel et al.(28) compared the microleakage of three bulkfill composite materials and one nanohybrid composite and found that the marginal gingival microleakage was higher than the occlusal onein all groups.Their findingsarein agreement with the presentstudy. However, such findingscontradict that by Deliperi and Bardwell(5),whofound no significant difference in dye penetration between occlusal and gingival microleakage scores. It is to be noted that 
the latter study examined different adhesive techniques for conventional restoratives, while this study examined a bulk filling protocol.

In the present study, the Filtek ${ }^{\mathrm{TM} B u l k F i l l ~ f l o w a-~}$ ble restorative material showed the highest microleakage score compared to the other two types ofrestorative materials irrespective of the application techniques used.This might be due to the inadequate adaptation to the enamel wall as a result of the low viscosity of resin composite.(29)On the other hand, X-trafil ${ }^{\circledR}$ BulkFill showed the lowest score of microleakage, which could be explained by the ratio of the lower surface rigidity value of the material to the upper surface rigidity value as anindicator of the polymerization rate.The polymerization rateof $\geq 80 \%$ issuccessful in preventing microleakage, and X-trafil ${ }^{\circledR}$ BulkFill meets this criterion.(30)This finding is in agreement with Siavash et al.(31), who showed that X-trafil ${ }^{\circledR}$ BulkFill composite restoration hadsmaller gaps at both dentin and enamel margins.

This study is limited by the fact that the dynamic intraoral thermal changes induced by drinking and eating could notbe simulated. In addition, the alternation of the dentinal surface after extraction and the absence of the outward flow of dentinal fluid can result in a poor correlation between in vivo and in vitro conditions, even though thermocycling is achieved in laboratory experiments. ${ }^{(32)} \mathrm{An}$ other limitation is the use ofa single version of adhesives systems for all types of composite restorations.

\section{Conclusion}

Both incremental and bulkfill application techniques using Tetric ${ }^{\circledR} \mathrm{N}-$ Ceram BulkFill, Filtek ${ }^{\mathrm{TM}}$ Bulk Fill flowable restorative material and X-trafil ${ }^{\circledR}$ Bulk Fill composite materials have a comparable effect on the marginal microleakage at occlusal and cervical margins of human teeth extracted from dental clinics in Sana's city. Further studies are recommended to assess the clinical success of bulkfill composite materials using SEM or confocal microscope.

\section{Ethical considerations}

The study protocol was approved by the Research Ethics Committee of the University of Science and Technology (MECA No.: EACIUST142).

\section{Acknowledgments}

The authors thank the staff of the College of Dentistry, University of Science and Technology, Sana'a,for providing the facilities and laboratory for the experimental work of this study.

\section{Authors' contributions}

AAA design the study, collected data, analyzed and interpreted data, and drafted the manuscript. AAM and MAD revised the manuscript. All authors approved the final submission.

\section{Funding}

University of Science and Technology funded this study.

\section{Competing interests}

The authors declare that they have no competing interests associated with this article.

\section{References}

1. Boruziniat $A$, Gharaee S, Sarraf Shirazi A, MajidiniaS, Vatanpour $M$. Evaluation of the efficacy of flowable composite as lining material on microleakage of composite resin restorations: A systematic review and meta-analysis. Quintessence Int.2016;47(2):93-101. DOI $\bullet$ PubMed $\bullet$ Google Scholar

2. Bayindir $Y Z$, Bayindir $F$, Zorba $Y O, H$ Turgut. Influence of different bonding systems and soft-start polymerization marginal gap formation. Mater Res Innovat.2008;12:166-71.

3. Karaman E, Keskin B, Inan U. Three-year clinical evaluation of class II posterior composite restorations placed with different techniques and flowable composite lining in endodontially treated teeth. Clin Oral Investig.2017;21(2):709-16. DOI • $\underline{\text { PubMed } \bullet ~}$ Google Scholar

4. Scotti N, Comba A, Gambino A, Salvatore P D, Alovisi M, Pasqualini $D$, et al. Microleakage at enamel and dentin margins with a bulk fills flowable resin. Eur J Dent.2014(1);8:1-8. DOI • PubMed $\bullet$ Google Scholar

5. Deliperi $S$, Bardwell DN. An alternative method to reduce polymerization shrinkage in direct posterior composite restorations. J Am Dent Assoc.2002;133:1387-1398. DOI • PubMed $\bullet$ Google Scholar

6. Unterbrink GL, Liebenberg WH. Flowable resin composites as "filled adhesives": Literature review and clinical recommendations. Quintessence Int. 1999;30(4):249-57. $\underline{\text { PubMed }} \bullet \underline{\text { Google Scholar }}$ 
7. Angeletaki F, Kogkos A G, Papazoglou E, Koukos D. Direct versus indirect inlaylonlay composite restorations in posterior teeth. A systematic review and meta-analysis. J Dent.2016;53:12-21. DOI $\bullet$ PubMed $\bullet$ Google Scholar

8. Ferracane JL, Hilton TJ. Polymerization stress -- Is it clinically meaningful? Dent Mater.2016;32(1):1-10. DOI • PubMed • Google Scholar

9. Agarwal RS, Hiremath $\mathrm{H}$, Agarwal J, GargA. Evaluation of cervical marginal and internal adaptation using newer bulk fill composites: An in vitro study. J Conserv Dent.2015;18(1):56-61. DOI $\bullet$ PubMed $\bullet$ Google Scholar

10. Nagpal R, Singh $P$, Singh S, Prabha Tyagi S. Proanthocyanidin: A natural dentin biomodifier in adhesive dentistry. J Rest Dent.2016;4:1-6. Google Scholar

11. Alvanforoush N, Palamara J, Wong RH, Burrow MF. Comparison between published clinical success of direct resin composite restorations in vital posterior teeth in 1995-2005 and 2006-2016 periods. Aust Dent J.2017;62(2):132-45. DOI • PubMed • Google Scholar

12. Jang JH, Park SH, Hwang IN. Polymerization shrinkage and depth of cure of bulk-fill resin composites and highly filled flowable resin. Oper Dent.2015;40:172-180. DOI • $\underline{\text { PubMed } \bullet}$ Google Scholar

13. Radhika M, Sajjan GS, Kumaraswamy BN, Mittal N. Effect of different placement techniques on marginal microleakage of deep class II cavities restored with two composite resin formulations. J Conserv Dent.2010;13(1):9-15. Oㅣ • $\underline{\text { PubMed } \bullet ~}$ Google Scholar

14. Frankenberger R, Hartmann V.E, Krench M, Kr $\square$ mer N, Reich S, Braun A, et al. Adhesive luting of new CAD/CAM materials. Int $J$ Comput Dent.2015;18(1):9-20. PubMed • Google Scholar

15. Vichi A, Margvelashvili M, Goracci $C$, Papacchini F, Ferrari M. Bonding and sealing ability of new self-adhering flowable composite resin in class I restorations. Clin Oral Investing.2013;17(6):149-506. DOI • PubMed • Google Scholar

16. Webber M, Majety KK, Pujar M. Bulkfill resin-based composites: microleakage of class II restorations. J Surg Clin Dent.2014;2(1):15-19. Google Scholar

17. Reddy SN, Jayashankar DN, Nainan M, Shivanna V. The effect of flowable composite lining thickness with various curing techniques on microleakage in class II composite restoration: an in vitro study. J Contemp Dent Pract.2013;14(1):56-60. DOI • PubMed $\bullet$ Google Scholar

18. Frankenberger R, Krämer N, Lohbauer U, Nikolaenko SA, Reich SM. Marginal integrity: is the clinical performance of bonded restorations predictable in vitro? J Adhes Dent. 2007;9(1):107116. PubMed $\bullet$ Google Scholar

19. Soares CJ, Celiberto L, Dechichi P, Fonseca RB, Martins LR. Marginal integrity and microleakage of direct and indirect composite inlays: SEM and stereomicroscopic evaluation. Braz Oral Res.2005;19 (4):295-301. DOI $\bullet \underline{\text { PubMed } \bullet \text { Google Scholar }}$

20. Arcos C, Díaz JD, Canencio K, Rodríguez D, Viveros C, Vega J, et al. In vitro description of macroscopic changes of dental amalgam discs subject to high temperatures to forensic purposes. J Forensic Odontostomatol.2015;33(1):8-18. - PubMed • Google Scholar

21. Mota CS, Demarco FF, Camacho GB, Powers JM. Microleakage in ceramic inlays luted with different resin cements. J Adhes Dent.2003;5(1):63-70. PubMed • Google Scholar

22. Öztürk F, Ersöz M, Öztürk SA, Hatunoğlu E, Malkoç S. Micro-CT evaluation of microleakage under orthodontic ceramic brackets bonded with different bonding techniques and adhesives. Eur $\mathrm{J}$ Orthod.2016; 38(2):163-9. DOI $\bullet \underline{\text { PubMed }} \bullet \underline{\text { Google Scholar }}$

23. Cenci MS, Pereira-Cenci T, Donassollo TA, Sommer L, Strapasson A, Demarco FF. Influence of thermal stress on marginal integrity of restorative materials. J Appl Oral

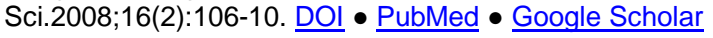

24. Rengo C, Spagnuolo G, Ametrano G, Goracci C, Nappo A, Rengo S. Marginal leakage of bulkfill composites in Class II restorations: a micro CT and digital microscope analysis. Int $\mathrm{J}$ Adhes.2015;60:123-9. DOI • Google Scholar

25. Idriss S, Habib C, Abduljabbar T, Omar R. Marginal adaptation of class II composite restorations using incremental and bulk placement techniques. J Oral Rehabil.2003;30(10):1000-7. DOI - PubMed $\bullet$ Google Scholar

26. Kuijs $\mathrm{RH}$, Fennis WM, Kreulen CM, Barink M, Verdonschot $\mathrm{N}$. Does layering minimize shrinkage stresses in composite restorations?J Dent Res. 2003;82(12):967-71. DOI • $\underline{\text { PubMed }} \bullet$ Google Scholar

27. Poggio C, Chiesa M, Scribante A, Mekler J, Colombo M. Microleakage in Class II composite restorations with margins below the $\mathrm{CEJ}$ : in vitro evaluation of different restorative techniques. Med Oral Patol Oral Cir Bucal.2013;18(5):e793-8. DOI $\bullet$ PubMed $\bullet$ Google Scholar

28. Patel $\mathrm{P}$, Shah $M$, Agrawal $N$, Desai $M$, Tailor $K$, Patel $K$. Comparative evaluation of microleakage of class II cavities restored with different bulk fill composite restorative systems: An in vitro study. J Res Adv Dent.2016;5(2):52-62. Google Scholar

29. Nazari A, Sadr A, Saghiri MA, Campillo-Funollet M, Hamba $H$, Shimada $Y$, et al. Non-destructive characterization of voids in six flowable composites using swept-source optical coherence tomography. Dent Mater. 2013;29(3):278-86. 미 • Google Scholar

30. Joseph A, Santhosh L, Hegde J, Panchajanya S, George R. Microleakage evaluation of silorane in human-based composite and methacrylate-based composite in class II box preparation using different layering techniques: An in vitro study. Indian $\mathrm{J}$



31. Savadi Oskoee S, Bahari M, Jafari Navimipour E, Ajami AA, Ghiasvand N, et al. Factors affecting marginal integrity of class II bulkfill composite resin restorations. J Dent Res Dent Clin Dent Prospects.2017;11(2):101-9. DOI $\bullet$ PubMed $\bullet$ Google Scholar

32. Yeolekar TS, Chowdhary NR,Mukunda KS, Kiran NK.Evaluation of microleakage and marginal ridge fracture resistance of primary molars restored with three restorative materials: A comparative in vitro study. Int J Clin Pediatr Dent.2015;8(2):108-113. DOI •

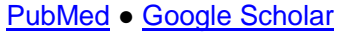

\section{Yemeni Journal for Medical Sciences}

To submit your manuscript to the journal through the online submission system, please use the following link: https://ust.edu/ojs/index.php/yimp/about/submissions

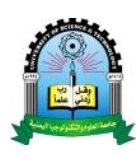

(c) 2020 University of Science and Technology, Sana'a, Yemen. This article can be unrestrictedly used, distributed or reproduced in any medium,provided that credit is given to the authors and the journal. Online ISSN: 2227-961X. 